Key Words

\title{
La difusión
}

\section{'anhelo de delgadez':}

\section{un análisis con}

\section{perspectiva de género}

\author{
Juan F. Plaza
}

\section{Profesor}

Facultad de Comunicación. Facultad de Comunicación. Universidad Pontificia de Salamanca. Henry Collet, 90-98, 37007, Salamanca (España) - Telf.: (+34) 923282750 - Email: jfplazasalupsa.es - Web: Www.upsa.es

\section{Resumen}

En las últimas décadas han aumentado exponencialmente los casos de anorexia, bulimia y otros trastornos alimenticios, especialmente en las adolescentes. Aunque las causas de estos desórdenes son múltiples, la investigación científica ha probado la influencia de los medios de comunicación y otros factores socioculturales en la sintomatología de los trastornos de la alimentación. Los mensajes de los medios destacan

\section{Abstract}

During the last decades, cases of anorexia, bulimia and other eating disorders have increased exponentttially, especially among adolescents. Although causes of these disorders are varied, scientific research has tested the influence of the media and other sociocultural factors in the symptomatology of eating disorders. Media messages repeatedly emphasize the beauty and thinness as a sign of prestige and social success for women. In this article, we analyze how is built a new mystique of femininity from a gender perspective, associated with the appearance and the desire for thinness, and their relationship to eating disorders. 
insistentemente la belleza y la delgadez como signos de prestigio y éxito social para las mujeres. En este artículo analizamos desde una perspectiva de género la construcción de una nueva mística de la feminidad asociada a la apariencia y al anhelo de delgadez, y su relación con los desórdenes alimenticios.

\section{Introducción}

Cada año 150.000 mujeres estadounidenses mueren de anorexia, según la Asociación de Bulimia y Anorexia (Wolf, 1991). En las adolescentes, la anorexia es la tercera enfermedad crónica más frecuente, tras la obesidad y el asma. Distintas investigaciones en Europa y Estados Unidos revelan grados importantes de insatisfacción con la apariencia y el propio cuerpo entre adolescentes de los dos sexos, especialmente entre mujeres, con porcentajes del $40 \%$ de las chicas y el 18\% de los chicos (Knauss, Paxton y Alsaker, 2008). Un meta-análisis reciente de la Universidad de WisconsinMadison en el que se han examinado más de 100 estudios que relacionan la exposición a los medios de comunicación, la insatisfacción corporal de las mujeres, la internalización de la delgadez ideal y los desórdenes alimenticios explica que aproximadamente el $50 \%$ de las chicas preuniversitarias dicen estar insatisfechas con sus cuerpos. Este sentimiento no sería trascendente si no tuviera consecuencias: la investigación ha identificado la insatisfacción con el propio cuerpo como uno de los más consistentes factores de riesgo de padecer trastornos de la conducta alimentaria (Grabe, Ward y Hyde, 2008).

Los distintos trabajos científicos a los que haremos referencia más adelante establecen conexiones entre diferentes trastornos alimentarios y la percepción del propio cuerpo, la autoestima, el ideal de delgadez imperante en una sociedad y otros factores de carácter sociocultural. Los medios no son, obviamente, los únicos agentes socioculturales que difunden y sustentan un determinado concepto de belleza, un patrón estético de delgadez más o menos inalcanzable o, en general, un modelo ejemplar de figura, pero su importancia por su penetración social y por la credibilidad que le otorgan los y las adolescentes (el grupo de mayor riesgo en enfermedades del comportamiento alimenticio) hace que sean punto de mira no sólo en el debate público no especializado, sino también en el estudio científico de la anorexia y la bulimia, en el que en no pocos trabajos ha considerado a los medios como una variable influyente más. 


\section{Objetivos}

Presentar las evidencias científicas acerca del papel de los discursos de los medios de comunicación de masas en el inicio, aceleración y desarrollo de la anorexia y la bulimia. Determinar las relaciones entre la delgadez normativa como valor supremo y su asociación al éxito personal y social, especialmente para las mujeres. Analizar críticamente los mensajes de los medios acerca de la belleza y el cuerpo desde una perspectiva de género.

\section{Metodología}

Tras realizar una revisión bibliográfica de las últimas investigaciones relativas a la importancia de los factores socioculturales (y, específicamente, de los medios de masas) en el desarrollo de la anorexia y la bulimia, se establecerán conexiones teóri- cas que nos sirvan de marco de análisis para entender las relaciones entre la imagen y el cuerpo ideales, la diferente ( $\mathrm{y}$ asimétrica) socialización de varones y mujeres en lo que se refiere a la apariencia física y los desórdenes alimenticios.

\section{Adolescencia, anorexia, bulimia y medios de comunicación}

¿Qué papel juegan los medios de comunicación social en el desarrollo de los trastornos alimenticios? ¿Son la causa de enfermedades como la anorexia y la bulimia o son un desencadenante, o más bien un acelerador, como la gasolina en un incendio? Es difícil afirmar taxativamente una correspondencia causa-efecto entre los discursos e imágenes sobre el cuerpo y la delgadez de los medios de comunicación y los desórdenes alimenticios, pero parece evidente que estos son el principal vehículo de difusión de aspiraciones estéticas inalcanzables para la mayoría de las mujeres y de los varones. Además, no hay que obviar que en torno al ideal de delgadez occidental se ha constituido un mercado con una importante cantidad de intereses económicos, presentes también en los media: remedios farmacéuticos, remedios naturales, la industria de la moda y la cosmética, etc. Detrás de un imperativo estético suele haber casi siempre una compleja maquinaria comercial, publicitaria y mediática (Ventura, 2000).

La preocupación social por los desórdenes de la conducta alimentaria va en aumento, aunque en los últimos años se ha logrado comprender mejor y tratar con eficacia 
algunos de las más importantes, como la anorexia o la bulimia. Sin embargo, están muy activas las discusiones sobre los orígenes de estas enfermedades: por ejemplo, sobre el peso que tienen los factores biológicos (predisposiciones genéticas, especialmente) frente a los factores socioculturales. Incluso algunos autores discuten la propia denominación de trastornos de la conducta alimentaria para englobar un conjunto heterogéneo de enfermedades relacionadas con los hábitos alimenticios, aunque no es este el lugar para discutir sobre esta terminología. En este artículo trataremos en exclusiva la anorexia y la bulimia, y presentaremos las evidencias científicas acerca del papel de los discursos mediáticos en el inicio, aceleración y desarrollo de estas enfermedades.

Como explica Josep Toro (1996) en El cuerpo como delito, en todas las culturas se han llevado a cabo procesos para modificar alguna característica corporal, pero nunca hasta el mundo moderno se ha pretendido aumentar el atractivo socio-sexual mediante la reducción o disminución de las dimensiones globales del cuerpo. Y es que el anhelo de delgadez y la voluntad de lograr una complexión diferente a través del control de la alimentación son claves para comprender enfermedades como la anorexia:

"La anorexia nerviosa es un trastorno del comportamiento alimentario caracterizado por una pérdida significativa del peso corporal (superior al 15\%), habitualmente fruto de la decisión voluntaria de adelgazar. El adelgazamiento se consigue suprimiendo o reduciendo el consumo de alimentos, especialmente 'los que engordan', y con cierta frecuencia mediante vómitos autoinducidos, uso indebido de laxantes, ejercicio físico desmesurado, consumo de anorexígenos y diuréticos, etc." (Toro, 1996: 7).

Por su parte, la bulimia nerviosa es un "trastorno del comportamiento alimentario caracterizado por la presencia de episodios críticos en los que la persona afectada ingiere cantidades de alimento significativamente superiores a lo que es normal ingerir en circunstancias similares" (Toro, 1996: 11). También en este desorden aparece la sensación de pérdida de control sobre los hábitos alimenticios.

La adolescencia es una etapa crítica en la construcción de una identidad personal global (y, por lo tanto, también en la formación de una identidad de género, más o menos coherente con los cánones sociales establecidos). Una época de cambio como ésta es también un momento de zozobra, en el sentido de que los y las adolescentes tienen una sensación de gran descontrol interno de muchas de las transformaciones que sufren, a la vez que caminan con incertidumbre hacia una madurez que no saben qué les deparará. Por estas razones, tratan de imponer el control, no siempre con éxito, como mecanismo de dominio sobre lo que le angustia. Así, muchas veces la comida se convierte en algo tangible que permite manipulación y que viene a repre- 
sentar lo que el adolescente, mujer o varón, querría controlar: su imagen como ideal (López Fuentetaja y Castro Masó, 2007).

Conformar una identidad es a la vez un proceso individual y relacional: supone tener conciencia de ser uno mismo y, a su vez, de ser distinto a los demás. En este camino de definición personal todos los factores referidos a la imagen corporal no son secundarios, ni mucho menos algo baladí: "No hay forma de imaginar quiénes somos, ni siquiera nosotros mismos, sin una imagen corporal. Ni en las descripciones más espirituales es posible representar a alguien sin un cuerpo y un rostro" (López Fuentetaja y Castro Masó, 2007: 31). Más aún, los distintos mecanismos de socialización imponen los referentes de los ideales de belleza que van a influir "no sólo en la construcción de la autoimagen y satisfacción corporal, sino también en el carácter de las relaciones entre los sexos, e incluso en el significado y experiencia de la sexualidad" (Pastor Carballo, 2004: 222).

En los medios de comunicación aparecen continuamente prototipos de belleza y comportamiento para las y los jóvenes, figuras ideales, modelos deseados y deseables que proponen un determinado canon estético ${ }^{\text {ii }}$. La mayoría de los contenidos de las revistas dirigidas a mujeres adolescentes están protagonizados por famosas de la música, el cine o el deporte, que son propuestas como referentes. Precisamente, en cuanto a los personajes famosos, Liebes (en
Huertas y França, 2001) plantea la siguiente hipótesis: la redefinición de la identidad durante la adolescencia es un proceso de negociación en el que la subjetividad se construye a través de modelos; en concreto, a través del diálogo entre los prototipos de los medios y las experiencias propias.

Pero el esfuerzo que hacen las chicas no es sólo para alcanzar un canon estético concreto: el fin último de tener un determinado aspecto, un determinado cuerpo, es la aceptación social. Ser atractiva es una de las condiciones imprescindibles del éxito (Plaza, 2007), y para las adolescentes merece la pena si la recompensa es la aceptación social, por grandes que sean las renuncias y los esfuerzos. Toro (1996) relata el origen de los primeros trastornos alimenticios de los que se tiene noticia en Occidente, referidos a tremendos ayunos que en casi todas las ocasiones ocasionaban la muerte, sacrificios ofrecidos a Dios, en la mayoría de los casos protagonizados por mujeres. Dice este autor que el ayuno y la abstinencia de anoréxicos y bulímicos se practican ahora en función de la belleza corporal y la aceptación social y añadimos que, quizá, son estas características las que ahora se colocan en los altares, las que se divinizan y son, por tanto, merecedoras de cualquier sacrificio.

En cualquier caso, desde hace casi dos siglos los medios de comunicación se convierten en los principales promotores de patrones estéticos; más aún, son partícipes importantísimos de un fenómeno de homo- 
geneización de las identidades de género en Occidente. No se puede obviar (y por eso le dedicaremos un capítulo en este artículo) que las mujeres son las principales afectadas por la anorexia y la bulimia (10 a 1 frente a los varones); y, desde luego, salvadas las explicaciones biologicistas, que en caso de comprobarse científicamente sólo esclarecen parcialmente el problema, es necesario recurrir a una interpretación crítica desde una perspectiva de género que nos ayude a entender por qué las mujeres (especialmente adolescentes) son víctimas mayoritarias de los trastornos de la conducta alimenticia, estrechamente ligados, como explicábamos, a la percepción de la delgadez ideal, la insatisfacción con el propio cuerpo y la exposición a los medios de comunicación.

\section{Factores socioculturales y trastornos alimenticios}

Las causas por las cuales un adolescente, varón o mujer, enferma de anorexia o de bulimia son múltiples. Es probable que existan agentes genéticos predisponentes, aunque la investigación científica apunta que en la bulimia los condicionantes biológicos son más importantes que en la anorexia. Lo que es innegable es la influencia en los trastornos de la conducta alimenticia de distintos factores socioculturales: los hábitos alimenticios, los modelos de los medios de comunicación, los valores asociados a la idea estética de la delgadez, la presión social ante el fenómeno de la belleza, etc.

Josep Toro (1996) ha dedicado su obra El cuerpo como delito: anorexia, bulimia, cultura y sociedad precisamente a analizar la trascendencia de los factores socioculturales en la explicación de los desórdenes alimenticios. El autor zanja desde el principio la discu- sión (un tanto maniquea) entre naturaleza y cultura como dos fuerzas opuestas y excluyentes, argumentando que los trastornos de la alimentación, especialmente anorexia y bulimia, son cuadros complejos y multicausados, y afirmando la trascendencia de poner a los fenómenos culturales en su justo lugar, como "importantísimos, que no exclusivos, agentes predisponentes, precipitantes y mantenedores de esas (...) enfermedades" (Toro, 1996: 7).

Pero el hecho de que algunas personas puedan estar predispuestas genéticamente o tengan un riesgo mayor de padecer algún trastorno alimenticio no justifica el incremento imparable de estos desórdenes, su circunscripción casi exclusiva a la cultura occidental (con sus valores, su idea de cuerpo ideal, su presión para conseguir la belleza...) y, lo que nos parece más trascendente, su mayor influencia en las muje- 
res (10 a 1 frente a los varones; 15 a 1 según otras fuentes). Así, para terminar esta discusión, Toro dice taxativamente: "En efecto, ciertos fenómenos socioculturales son intrínsecos a la génesis de la anorexia, la bulimia y otras anomalías afines. Es más, sin ellos con seguridad no existiría la actual 'epidemia', y, además, probablemente ni la anorexia ni la bulimia revestirían su actual morfología, su presentación contemporánea" (1996: 7).

\subsection{La difusión mediática del ideal de delgadez}

Los medios de comunicación de masas difunden los patrones estéticos imperantes en Occidente, en los que la delgadez es, sin lugar a dudas, uno de los valores fundamentales. Los contenidos referidos a la moda y al cuidado corporal ocupan un espacio preeminente en las revistas femeninas. En el caso de las publicaciones dirigidas a chicas adolescentes, además, los famosos y las famosas (que también responden a un determinado prototipo estético) se configuran para las más jóvenes como arquetipos de belleza y de comportamiento deseados y deseables (Plaza, 2005).

"Todas estas modelos corporales de nuestra peculiar cultura constituyen a ojos de muchas mujeres y la mayoría de las jovencitas la quintaesencia de la belleza y el éxito. Aparecen en todos los medios de comunicación rodeadas del prestigio social que sólo otorga la reverencia masiva de las gentes, provocadas y azuzadas por los comerciantes en modas ayudados por inteligentísimas campañas de mercadotecnia, de promoción y lanzamiento publicitario" (Toro, 1996: 243).

¿Cuál es la responsabilidad de los medios de comunicación? Consciente o inconscientemente, son un factor en el desarrollo y mantenimiento de los trastornos de la alimentación y los desórdenes relacionados con la imagen. Como mostraremos más adelante, distintos estudios vinculan directamente la exposición a los medios y la experimentación de sintomatología alimentaria, mediada por la interiorización de las presiones culturales.

Desde nuestro punto de vista, es imprescindible evaluar la transmisión social de los valores corporales desde una perspectiva de género. Como dice Rosa Pastor (2004: 230):

"La presión cultural de los modelos ideales sobre la belleza y el atractivo repercute en la auto-imagen de varones y mujeres, causando efectos [diferenciales] en las estrategias de acercamiento entre los sexos, pero también origina graves desajustes en la valoración de la propia imagen, en cuyo origen pueden estar importantes trastornos psicológicos”.

Así, las influencias socioculturales pueden ser un buen predictor de la insatisfacción de varones y mujeres, aunque los varones tienen una mayor facilidad para ignorar las presiones sociales en torno al cuerpo (algunas de ellas, al menos) frente a la mayor 
vulnerabilidad de las mujeres. Volveremos sobre esta idea más adelante.

Qué duda cabe que las revistas femeninas están en el punto de mira por su responsabilidad en la difusión de determinados patrones estéticos y la exaltación de algunos valores relacionados con el culto al cuerpo y la veneración de la delgadez como bien supremo. Es verdad que, en cierta medida, las revistas no inventan esos valores: propagan unos ideales que ya existen. Pero es igualmente cierto que éstas forman parte de un entramado comunicativo en el que es abrumadora la presencia de esos ideales, en donde se produce una repetición continua y a través de diferentes medios de los mensajes acerca de la imagen personal, que además suelen estar asociados a cuestiones emocionales y de identidad; igualmente, los medios adolecen de patrones corporales alternativos que tengan éxito, alejados del estándar delgado imperante.

Y es que delgada y éxito son palabras sinónimas. La delgadez se asocia a elegancia, a prestigio. Ropa elegante y figura elegante son, en el imaginario simbólico, iguales a delgadez. Cuidar el cuerpo supone estar delgada. Quien no está delgada no puede llevar ropa de prestigio. Y estas asociaciones suelen estar alejadas de cualquier reflexión racional y, más bien, forman parte de un elenco de creencias y sentimientos profundamente sentidos e interiorizados que, de hecho, muchas veces gobiernan nuestras vidas. Los mensajes sobre belleza y moda suelen utilizar un lenguaje emotivo, impresionista, poco argumentativo, pero muy eficaz.

Por supuesto, los medios de comunicación en general y las cabeceras dirigidas a mujeres se defienden de estas acusaciones. Alegan que no son responsables de las decisiones que (¿libremente?) toman las chicas y las mujeres adultas, y argumentan que no está demostrada la relación causa-efecto entre, por ejemplo, las campañas de publicidad y la anorexia. Igualmente, declaran que hacen esfuerzos cada vez mayores por que la información sobre los trastornos alimenticios se incremente y sea y de una mayor calidad, evitando (con desigual éxito) frivolidades en estas informaciones. De la misma forma, algunas publicaciones intentan explícitamente ofrecer modelos alternativos, mujeres que responden a patrones estéticos distintos y menos peligrosos para la salud con las mujeres corrientes puedan identificarse o proyectarse (Argente del Castillo, 1999).

La realidad es que, como hemos explicado, las mujeres se ven mucho más afectadas de anorexia y bulimia que los varones, a pesar de que a estos les interesa también su cuerpo (aunque de otro modo). Thompson y Heinberg (1999) recogen en su trabajo sobre la influencia de los medios en los desórdenes vinculados con la imagen corporal y la alimentación algunas investigaciones que han hallado que un $70 \%$ de las lectoras de revistas femeninas reconocen a estas publicaciones como una importante 
fuente de información sobre belleza y estado físico. En el caso de las adolescentes, la influencia de los patrones estéticos es mayor: en la adolescencia se viven las emociones y los objetivos vitales de manera apasionada. Para las chicas más jóvenes, consumir medios de comunicación (revistas especialmente) es relativamente fácil y coherente con su cultura juvenil. La investigación científica revela que el ideal de las modelos de belleza que admiran las chicas tiene proporciones que son peligrosas para la salud. Así, en la versión más extrema del arquetipo encontraríamos una mujer con un índice de masa corporal de 16, que correspondería a alguien con anorexia.

El "anhelo de delgadez" es, por tanto, un factor de origen sociocultural que afecta especialmente a las mujeres, y particularmente a las adolescentes. Este deseo constante, permanente e incesante de ser delgada provoca que muchas mujeres, jóvenes y adultas, tengan una preocupación excesiva y desproporcionada por su cuerpo, además de una percepción negativa de todo o parte de su figura: es lo que se conoce como trastorno dismorfofóbico (López Fuentetaja y Castro Masó, 2007). Especialmente importante en el desvelo por la propia imagen corporal es la preocupación por el cuerpo como afirmación personal y como forma de autosatisfacción para aumentar la autoestima, algo que tiene una trascendencia mayor en esta etapa:

Lo que ella espera [las autoras se refieren al caso concreto de una adolescente] de su del- gadez es 'sentirse bien' con ella misma, como si ella supiera claramente quién es, y su identidad no estuviera sostenida en este momento únicamente por su capacidad de control sobre su cuerpo. Afirma que lo que busca es 'conseguir una especie de paz para siempre', siendo un objetivo más parecido a la muerte que a la vida, y eso sólo lo puede lograr de esa forma. Se sigue viendo gorda, porque para ella ser gorda es lo mismo que ser imperfecta y ésa es la versión insoportable que tiene de sí misma (López Fuentetaja y Castro Masó, 2007: 197).

El anhelo de delgadez no conoce fronteras geográficas, económicas o de clase. El colonialismo cultural de occidente, la globalización de las identidades de género y la democratización y homogeneización de la información ( $y$, por tanto, de la difusión de valores comunes) a través de los medios de masas está provocando que la anorexia, la bulimia y otros trastornos penetren a través de las culturas, las estructuras económicas y los tejidos sociales. De hecho, durante mucho tiempo la anorexia ha sido una enfermedad occidental, además de un trastorno que correlacionaba con el nivel socioeconómico (sólo los ricos [las ricas] podían "permitirse" ser anoréxicos). Su manifestación, tal y como la conocemos ahora, está estrechamente ligada al desarrollo de los medios de comunicación de masas, que han actuado como agentes homogeneizadores interclasistas de modas $y$ costumbres (Toro, 1996: 92). Así, el hecho de que la anorexia y la bulimia se 
estén haciendo cada vez más frecuentes en lugares y colectivos a los que antes apenas afectaba no hace sino reforzar la idea de lo importantes que son los factores socioculturales en el desarrollo de estos desórdenes.

Thompson y Heinberg (1999) afirman que ha sido claramente demostrado que los medios impresos y la televisión afectan al sentimiento individual de la imagen corporal. La exposición a las revistas y la televisión puede llevar a alteraciones de la alimentación, insatisfacción corporal y otros trastornos, incluso ante exposiciones mínimas a estos contenidos. Knauss y colaboradoras (2008) proponen un modelo teórico para explicar la insatisfacción con el propio cuerpo en chicos y chicas suizos. Como a otros investigadores, les llama la atención el hecho de que sean las chicas las que mayores trastornos relacionados con su propia imagen presentan y las que también revelan una mayor preocupación por su cuerpo. Algunos estudios dicen que la internalización de una idea de cuerpo, de un cuerpo modelo, y la presión que se percibe de los medios en cuanto a ajustarse a una figura utópica no son sólo factores predictores de un cuerpo objetivo, sino también predictores de la insatisfacción corporal en adolescentes y preadolescentes.

Películas, programas de televisión, revistas, actores y actrices... muchos discursos públicos enfatizan la delgadez. Los personajes extremadamente delgados están sobrerrepresentados, mientras que las personas con sobrepeso están infrarrepresentadas. De acuerdo con algunas teorías de la comunicación como, por ejemplo, la Teoría del Cultivo, la exposición repetida a los contenidos de los medios lleva a los espectadores a aceptar las representaciones de mujeres y hombres como representaciones de la realidad $^{\mathrm{iii}}$, es decir, que las representaciones de la delgadez ideal pasan a ser normativas, deseables, esperadas y aspectos centrales de la belleza femenina (Grabe, Ward y Hyde, 2008: 460).

\subsection{La investigación científica acerca de la influencia de los medios en los trastornos alimenticios}

Parece evidente que los medios de comunicación son importantes en nuestras vidas. Podemos considerarlos como agentes socializadores de primer orden, como la familia, la escuela o el grupo de pares. Por su propia naturaleza, difunden un arsenal extenso de historias (algunas de ficción, otras no) a través de distintos canales. Tienen una alta penetración en todas las capas sociales, además de un poder de convocatoria y de seducción innegables. Sin embargo, y aquí viene la dificultad para quienes pensamos sobre ellos y sus influencias, es extremadamente complicado conocer cuál es su verdadero influjo en la vida de las personas. 
¿Qué impacto tienen las historias que cuentan los medios en las identidades de la gente? ¿Qué influencia tienen en la formación de nuestra personalidad y, aún más, en nuestra definición como hombres y mujeres, en la construcción de una identidad de género? Los medios de masas divulgan muchísimas imágenes y mensajes acerca de hombres y mujeres y de sus relaciones, por lo que es altamente improbable que estas ideas no tengan algún impacto en nuestro propio sentido de la identidad. Por otro lado, parece igualmente improbable que esos efectos sean totalmente directos, puesto que es difícil que una persona copie o tome prestada su identidad directamente de una revista o de la televisión.

La dificultad para medir estos efectos no es óbice, sin embargo, para que los medios de comunicación sean objeto de estudio y análisis desde distintas disciplinas. En el caso que nos ocupa aquí, el de los factores socioculturales asociados a la anorexia, la bulimia y otros trastornos, ya hemos dejado clara cuál es la trascendencia de estos agentes. Desde nuestro punto de vista, es necesario completar la reflexión meramente teórica (válida, pero no suficiente) con los trabajos científicos que en los últimos años sugieren que la exposición a los media y la representación de un cuerpo ideal delgado tiene algún tipo de nexo con la imagen corporal y las alteraciones de la imagen en las mujeres especialmente (Castillo Pachón, 2006; Grabe, Ward y Hyde, 2008; Guerro-Prado y Barjau
Romero, 2002; Guerro-Prado, Barjau Romero y Chinchilla Moreno, 2001; Knauss, Paxton y Alsaker, 2007, 2008; Thompson y Heinberg, 1999; Toro, 1996).

De todos los estudios que podemos citar nos parece especialmente relevante el de Grabe, Ward y Hyde (2008), Role of the media in body image concerns among women: $A$ meta-analysis of experimental and correlational studies. En él, las autoras realizan un metaanálisis en el que han examinado más de 100 estudios experimentales y de correlación que relacionan la exposición a los medios, la insatisfacción corporal de las mujeres, la internalización de la delgadez ideal y los desórdenes alimenticios.

¿Por qué este meta-análisis? Pues porque algunos de los trabajos acerca de los posibles efectos de los media en desórdenes relacionados con la valoración negativa de la propia imagen e incluso de la aparición o del refuerzo de sintomatología de trastornos alimenticios dejan algunas dudas, la mayor parte de ellas metodológicas. En realidad, aunque parece evidente que existe algún tipo de nexo, no se tiene claro cuál es la "fuerza" de esa vinculación ni tampoco por qué algunas investigaciones devuelven resultados nulos. Una revisión en profundidad de los estudios científicos de las últimas décadas revela la utilización de una variedad de estímulos, medidas y metodologías para un mismo fin: encontrar la correspondencia entre la exposición a los modelos de los medios y la percepción de 
la propia imagen. Grabe y colaboradores hacen el esfuerzo de rescatar todas las variables utilizadas y agruparlas en cuatro grandes categorías: la insatisfacción con el cuerpo, la autoconciencia del cuerpo, la internalización del ideal de delgadez y los comportamientos y creencias acerca de la alimentación.

En su revisión encuentran dos clases de investigaciones:

1. Trabajos que examinan las conexiones entre el uso de los medios y las imágenes de los cuerpos femeninos que han tratado de explicar a través de experimentos de laboratorio si la exposición a distintos contenidos mediáticos sobre la delgadez ideal incrementa la insatisfacción corporal. Estos estudios, aunque arrojan datos interesantes para entender los efectos de los medios sobre la imagen corporal pecan - tal y como aclaran Grabe y sus colaboradores (2008) - de una cierta artificialidad y, por tanto, limitan de alguna manera su validez externa. La mayoría de estas investigaciones han utilizado métodos experimentales para comprobar si se intensifica la insatisfacción corporal femenina después de exponerlas a imágenes de modelos delgadas, y verificar que no varía esta percepción ante la contemplación de imágenes neutras. Los resultados son concluyentes: una parte importante de investigaciones experimentales indican que la exhibición de prototipos míticos aumenta la insa- tisfacción corporal y la sintomatología de los trastornos alimenticios. Eso sí, parece que esto es más cierto o que el efecto es mayor en mujeres que antes de los experimentos ya estaban insatisfechas con sus cuerpos.

2. Otro tipo de investigaciones con datos correlacionales (naturalistics, los califican los autores) indaga en la ligazón entre el consumo de medios de las mujeres y su insatisfacción corporal. En este caso, los datos indican que una mayor exposición a revistas femeninas o a programas televisivos que muestran modelos con una delgadez ideal se asocia con mayores niveles de insatisfacción corporal y sintomatología de trastornos alimenticios en mujeres y chicas jóvenes. Estos estudios son especialmente valiosos cuando se combinan con resultados obtenidos en situaciones reales, no de laboratorio, y otros trabajos en los que los sujetos dan cuenta de su uso real de los medios.

La bondad principal a nuestro juicio de la revisión de Grabe, Ward y Hyde es que realizan una exhaustiva investigación sistemática de todas las conexiones globales entre la delgadez ideal que muestran los medios, la insatisfacción corporal, la internalización de los modelos de delgadez y los comportamientos y creencias sobre la alimentación. Los resultados de su metaanálisis muestran asociaciones consistentes entre las variables que se emplean en los distintos estudios analizados, por lo que 
queda clara así la idea de que existen relaciones científicamente probadas entre las representaciones de un cuerpo delgado y las alteraciones y vulnerabilidades de las mujeres vinculadas con su figura.

En este meta-análisis se confirma la hipótesis de que las mujeres expuestas a la delgadez mítica de los medios puntúan más alto en las valoraciones de actitudes unidas a anorexia, bulimia y otros desórdenes. En cuanto a la insatisfacción con el propio cuerpo, parece que la exposición a los medios de comunicación está asociada con niveles decrecientes de agrado con su aspecto en las mujeres.

\section{La construcción de una identidad femenina, los discursos mediáticos $y$ los desórdenes alimenticios. Análisis con perspectiva de género}

Si hasta ahora hemos argumentado la importancia de los factores socioculturales en el desarrollo de los trastornos relacionados con la alimentación; si los y las especialistas ponen en valor las presiones sociales sobre la imagen y el cuerpo ideal y su vinculación con la percepción del propio cuerpo y la autoestima; y si desórdenes como la anorexia y la bulimia afectan de manera prioritaria a mujeres, parece que necesariamente hemos de hacer alguna reflexión crítica que conecte estas ideas con lo que social y culturalmente significa para las mujeres la apariencia y, en especial, la delgadez. Es imprescindible, desde nuestro punto de vista, incorporar un marco interpretativo que ofrezca una perspectiva global, estructural; y los indicadores de género son herramientas analíticas muy útiles de observación multidisciplinar. De esta forma, la variable 'género' se constituye en un instrumento provechoso para el estudio de las distintas realidades sociales $\mathrm{y}$, por supuesto, de los contenidos de los medios de comunicación de masas. No en vano el concepto 'género' remite a factores culturales que configuran lo que son los hombres y las mujeres en el espacio social, y a través de él se entiende lo masculino y lo femenino como dimensiones simbólicas, culturales y, por lo tanto, construidas, cambiantes.

No es azaroso, por este motivo, que estos trastornos afecten tanto y tan desproporcionadamente a las mujeres. Sin desdeñar las posibles influencias biológicas (más importantes en la bulimia que en la anorexia), la valoración sociocultural del cuerpo de la mujer (tan diferente a la valoración del varón) y las presiones sociales para que "encajen" (nunca mejor dicho) en un 
determinado modelo estético hacen que necesariamente tengamos que valorar la relación cultura-imagen-cuerpo-feminidad. La estimación social y personal del cuerpo está drásticamente determinada por la cultura ambiental y, desde luego, los desfases entre el canon propuesto y el personal son fuente de malestar y ansiedad.

Rosa Pastor (2004: 218) explica que "el cuerpo, que forma parte fundamental de nuestro imaginario y configura nuestra identidad, es significado de forma genérica”, esto es, que la cultura occidental ofrece definiciones distintas (y asimétricas) de lo que supone un cuerpo de mujer o de varón. En cierta medida, el "cuerpo generizado" es un soporte que reproduce las relaciones de desigualdad entre los sexos; se define corporalmente a hombres y mujeres en oposición y asimetría (Pastor Carballo, 2004: 219). La identidad de género es el resultado de un proceso evolutivo por el que se interiorizan las expectativas y normas sociales relativas al dimorfismo sexual, y hace referencia al sentido psicológico del individuo de ser varón o mujer con los comportamientos sociales y psicológicos que la sociedad designa como masculinos o femeninos (Martínez Benlloch y Bonilla Campos, 2000: 90). Desde este punto de vista, las personas extraemos información para construir nuestra identidad de género de múltiples fuentes, entre las que se encuentran los medios de comunicación.
En ese proceso de formación de una identidad, en el que están implicados factores cognitivos, emocionales y relacionales, es fundamental la construcción de la propia imagen, la visión global de quién es uno o una. Nuestro cuerpo y nuestro rostro son nuestra primera "carta de presentación”. En el caso de las mujeres, apariencia y feminidad han ido históricamente muy estrechamente unidas. La "mística de la feminidad" de la que hablaba Betty Friedan pasa actualmente, entre otras cosas, por la vorágine de lograr una belleza que cada vez presenta exigencias más grandes.

\subsection{Identidad $y$ belleza: ¿una cárcel para las mujeres?}

Esta mística de la feminidad ha estado asociada a la consecución de una suerte de “domesticidad virtuosa" (Wolf, 1991), y era ése el valor social básico de la mujer; ahora es el mito de la belleza el nuevo valor principal para las mujeres, la lucha permanente (y siempre fallida) por una belleza virtuosa. Estar siempre bella es la condición primera del éxito, algo que se convierte en mito, en cárcel de oro, una quimera que ejerce labores de control social. En palabras de Naomi Wolf (1991: 13): "Pasada una generación, ¿se sienten libres las mujeres? Las mujeres ricas, educadas y liberadas del Primer Mundo, las que gozan de libertades que nunca antes estuvieron al alcance de una mujer, no se sienten tan liberadas como desearían". 
Wolf (1991: 55) aclara que antes de que las mujeres se incorporasen masivamente al mercado laboral sólo unas pocas ejercían profesiones en las que se las remuneraba explícitamente por su belleza (por cierto, profesiones poco respetadas, en general): modelos, actrices, bailarinas y acompañantes. Lo que sucede en la actualidad es que para las mujeres ser-estar bellas es un requisito imprescindible en profesiones y oficios muy alejados de las tradicionales profesiones de exhibición. "Profesional pero femenina" (femenina quiere decir, en realidad, "atractiva”) es, por ejemplo, un leitmotiv en las revistas dirigidas a mujeres.

Desde hace varios años el filósofo José Antonio Marina sigue periódicamente estas publicaciones para averiguar cómo van cambiando los estereotipos femeninos, y no deja de llamarle la atención su obsesivo interés por la belleza. Dice Marina que los mensajes que se les dan a las mujeres son contradictorios, porque se las llama a la liberación mediante la sumisión:

"La belleza se convierte en modo de afirmación de la voluntad femenina. Y también, por supuesto, en fuente de frustración permanente, porque no hay nada más sometido al fracaso que las dietas de adelgazamiento" (Marina, en Ventura, 2000: 16).

En este sentido, hay cientos de ejemplos en las revistas femeninas que vinculan apariencia e identidad, y, por supuesto, delgadez con identidad. Por ejemplo, algunos de los artículos que aparecen en estas publicaciones relacionan un cambio de look, un cam- bio de apariencia, con nuevas oportunidades en la vida o con una mayor autoestima. Un lector neófito de las cabeceras dirigidas a mujeres podría pensar que cuando las mujeres quieren cambiar de vida... adelgazan.

Pero ¿por qué a los varones les interesa su figura igual que a las mujeres $y$, sin embargo, caen menos en la anorexia? Josep Toro (1996) explica que la anorexia en hombres y mujeres es distinta, por ejemplo, porque los varones anoréxicos son mayoritariamente obesos antes de iniciar su trastorno, frente a un porcentaje pequeño de chicas que lo son. Además -insiste este psiquiatra- los chicos suelen ser más deportistas y no buscan exactamente una complexión delgada, sino estar atléticos, ya que el estereotipo masculino está definido por la amplitud torácica y la imagen de fuer$\mathrm{za} /$ potencia física. Los varones experimentan desde pequeños mayor presión social para hacer ejercicio físico ("moldeamiento activo"), frente a las chicas, que suelen practicar lo que Toro llama la "decoración pasiva" de sus cuerpos. Aunque las expresiones que emplea Toro pueden ser más o menos discutibles, más o menos afortunadas, su argumentación nos conduce, de nuevo, a argumentos no biológicos (socioculturales) y, necesariamente, a un planteamiento crítico desde una perspectiva de género. Es evidente que la percepción social del cuerpo femenino y del varonil no es la misma: 
“(...) Mientras que las acciones de un hombre señalan los hitos de su historia personal, se nos ha hecho creer que la identidad de una mujer está vinculada intrínsecamente a la percepción del cuerpo: la suavidad o aspereza de la piel, el pecho, la sexualidad, la maternidad, la crianza, las arrugas, el envejecimiento, son aspectos que las mujeres interiorizan como si fueran sus únicas señas de identidad. (...) En una sociedad que ha exacerbado la importancia de la imagen, la persecución de la belleza sigue gravitando sobre la biografía de las mujeres" (Ventura, 2000: 20).

Las revistas, la televisión, la publicidad... nos bombardean con cientos de cuerpos delgados (a veces con una delgadez extrema). Los discursos públicos que vehiculan los medios (no todos, afortunadamente, pero sí una mayoría) unen con frecuencia la autoestima de las mujeres con su apariencia física y con su figura. Las mujeres aparecen preferentemente representadas como sujetos sexuales (casi siempre pasivos), objeto de deseo de los varones. Pero esto no es sólo una percepción fruto de un análisis superficial: son conclusiones obtenidas en distintos trabajos. En el caso que nos ocupa, el de la relación de los medios de comunicación y los desórdenes alimenticios, son muy interesantes las conclusiones de un estudio con adolescentes de ambos sexos de las universidades de La Trobe (Australia) y la de Berna, en Suiza: en él se demuestra que las chicas presentan una tendencia significativamente más alta que los chicos a tener 'conciencia de cuerpo objetivado' (objectified body consciouness). Este concepto, con una larga trayectoria en la investigación científica, revela cómo la construcción social del cuerpo femenino hace que las mujeres aprendan a ver sus propios cuerpos desde la perspectiva de un observador externo. Como dice John Berger, a lo largo de la historia el cuerpo de las mujeres se ha concebido a través del reconocimiento de las palabras de otros: "Los hombres miran a las mujeres. Las mujeres se contemplan a sí mismas siendo miradas. Este hecho determina no sólo la relación entre hombres y mujeres, sino también la relación de la mujer con ella misma" (en Ventura, 2000: 25).

No se puede, por tanto, entender la construcción social del cuerpo femenino sin acudir a la Sociología y la Psicología diferencial, a una perspectiva de género que dé una interpretación satisfactoria a por qué las mujeres son más vulnerables que los varones e internalizan el ideal físico de los medios significativamente más que los chicos (Knauss, Paxton y Alsaker, 2008). Además, las mujeres manifiestan una tendencia mayor que los varones a centrar la atención e identificarse con partes que son objetivadas por los demás y juzgadas por su aspecto, mientras que los varones, sin embargo, lo hacen con aquellos aspectos físicos considerados en su funcionalidad instrumental. La explicación de las diferencias puede residir, a juicio de Rosa Pastor (2004) en la dicotomía pasivo/activo del 
estereotipo de la feminidad y la masculinidad, respectivamente. Desde este supuesto, las mujeres, centradas en el cuerpo objeto, atenderían a partes individuales, que son evaluadas con respecto a los modelos de atractivo y, por tanto, dependientes de la mirada del otro, mientras que los varones, al hacerlo sobre el cuerpo como proceso, responderían también a una evaluación estereotípica, pero desde la perspectiva de la actividad y la dinámica, relacionada con la socialización en la acción y no en la apariencia y belleza.

En definitiva, la presión social sobre las mujeres, sus cuerpos y su apariencia hace que ellas se enfrenten, en distintos contextos, a la exigencia de ser juzgadas por su aspecto físico, algo a lo que, por cierto, también se enfrentan los hombres, pero de distinta forma:

"Algo en su interior [en el de los hombres] les dice que el poder económico, los logros profesionales, el talento, la fuerza física, la celebridad, la jerarquía, o, simplemente, la simpatía y la capacidad de seducción (al margen de sus anatomías), les protegen de la insignificancia o decadencia de sus cuerpos" (Ventura, 2000: 27).

En realidad, y volviendo a los medios de comunicación entendidos como industrias culturales, las mujeres tienen muy pocos modelos en el mundo, excepto los de las revistas, frente a los hombres, que tanto en el cine como en la literatura, la política, el deporte o los negocios tienen referentes sobrados, lo que quizá explicaría en arte
- como apuntábamos antes- que los hombres no estén expuestos a los arquetipos ideales de la misma forma que las mujeres.

\subsection{Las revistas para adolescentes $y$ el éxito de la apariencia}

Para terminar estas reflexiones acerca de los factores socioculturales y su relación con la anorexia y la bulimia, debemos referirnos a un medio de comunicación concreto: las publicaciones dirigidas a chicas adolescentes. Ya hemos hecho referencia anteriormente a las revistas femeninas y a la polémica que las rodea en cuanto a la reproducción de estereotipos de género. En cualquier caso, desde nuestro punto de vista las cabeceras dirigidas a un público adolescente presentan un matiz cualitativamente distinto a sus homónimas para adultas: la audiencia a la que están dirigidas.

Los procesos mentales de este periodo vital están dirigidos prioritariamente a consolidar lo que al individuo le hace único y diferente a los otros, es decir, su identidad. En este proceso adolescente hay una parte de identidad que permanece y otra nueva que se descubre. En esta etapa, la importancia que se le da a la apariencia física es vital, hasta el punto de que se le otorga un papel determinante en el mundo de las relaciones. Así, frecuentemente identidad e imagen corporal se confunden: "La cons- 
trucción de la propia imagen (...) es un proceso de carácter evolutivo complejo, que va intrínsecamente unido a la constitución de la identidad” (López Fuentetaja y Castro Masó, 2007).

Muchas de las preocupaciones sobre el aspecto personal están profundamente ligadas a lo que otros pudieran pensar. La idea imperante de la delgadez (de la que todos participamos, en mayor o menor medida) se configura como un medio para conseguir la autoestima y la aceptación social. Josep Toro explica que existe correlación entre evaluar positivamente las características físicas propias (apariencia y salud) y una buena adaptación psicológica (y al revés). Socialmente la idea de delgadez es señal de bienestar y éxito. Este psiquiatra afirma que se ha incrementado la insatisfacción por la apariencia física, hasta el punto de que el 95\% de las mujeres sobreestiman el volumen de sus cuerpos: "Es como si, aceptando la presión social, todos nos hayamos llegado a convencer de que somos deformes, hipertróficos, dilatados" (1996: 140).

Las adolescentes reconocen que las conversaciones sobre el peso o el aspecto físico son sumamente frecuentes entre el grupo de coetáneas. La mayoría dice que envidian a las chicas capaces de seguir una dieta o régimen de adelgazamiento. A la envidia de la complexión delgada y estructurada se le añade la envidia a la "fuerza de voluntad" evidenciada por quien consigue adelgazar. Esto es importante en la anorexia nerviosa, porque forma parte del perfeccionismo con que el paciente anoréxico pretende juzgarse a sí mismo.

Las revistas para quinceañeras manejan de manera transversal un discurso que bebe directamente de la cultura del éxito total (Plaza, 2007). Así, si dedican un reportaje a cómo relacionarse con los varones, la clave está en cómo ligar más, en cómo derrotar a una competidora en la conquista de un chico o en cómo vencer esa "terrible maldición” que consiste en no tener pareja. La puerta de entrada al éxito es gozar de una buena apariencia: los consejos de belleza, las páginas de moda o las dietas adelgazantes dibujan un canon estético que hay que lograr para ser aceptada socialmente, para gustar por encima de todo. Además, la apariencia está absolutamente ligada a la feminidad, a la construcción de una concreta (y reductora) identidad de género. Las lectoras tienen, además, el ejemplo de los personajes famosos, que actúan como referentes y que suponen la sublimación del éxito, su encarnación.

Las revistas plantean a las chicas qué deben hacer para ser mujeres, o mejor, convertirse en mujeres. Las adolescentes, tal y como son reflejadas en las revistas, tienen muy claro que el mero hecho biológico de pertenecer a un sexo no garantiza la feminidad: ésta se alcanza. ¿Y cómo se logra ser toda una mujer? Básicamente, a partir de tres principios imbricados que actúan como condiciones de la feminidad: una apariencia bella, unos determinados comportamientos 
adecuados o inadecuados y, especialmente, la orientación hacia el otro sexo, la relación con los chicos.

Es evidente que la belleza constituye uno de los pilares sobre los que se asientan de forma transversal los contenidos de las revistas. No hay más que ojear las páginas de cualquier cabecera para concluir que sus fotografías muestran un modelo específico de mujer, un canon estético que se concreta en un aspecto joven y delgado. Además de las imágenes, otros elementos remiten a este contenido: la publicidad; los artículos y las secciones sobre moda, maquillaje o dietas; los consejos y guías para ser bella; las noticias, entrevistas y reportajes sobre famosos y famosas, que no sólo se ajustan al canon establecido sino que, además, son destacados por su aspecto en el discurso periodístico.

Alcanzar la belleza es algo más que la consecución de una simple apariencia, es parte de la esencia de la feminidad que se construye en los mensajes de estas publicaciones y, además, es un medio imprescindible para lograr el éxito que, en última instancia, suele consistir en la conquista de los chicos (aunque no únicamente, porque ser atractiva es también un medio para ser popular). Trabajar el aspecto físico tiene un doble sentido, aunque en ambos casos se promete el éxito teñido de felicidad y bienestar personal. En primer lugar, ser bella es un triunfo individual, una inyección de autoestima; en segundo lugar, la imagen tiene un sentido relacional, supone estar guapa para los demás (para los chicos, esencialmente), ser y estar sexy es esencial en esa especie de "competición compulsiva" dirigida a conquistar adolescentes varones.

Incluso en un tema tan delicado como la anorexia se plantea el "ligoteo" como motivación final para salir de la enfermedad. Por ejemplo, la revista Súper Pop, en su número 731 , dedica un reportaje a la anorexia y la bulimia, con la participación además de una especialista. En el texto se definen la anorexia y la bulimia, se explican sus causas y se trata de instruir en la identificación de las señales de alarma; al final, se avisa de las consecuencias físicas, psíquicas y sociales. Básicamente, sugieren a las adolescentes que esta enfermedad supone la pérdida de la belleza y de las relaciones sociales. En un pequeño despiece se advierte: "A los chicos... ¡les encantan las chicas con curvas!".

\section{Conclusiones}

Estar delgado o delgada se está convirtiendo - si no lo es ya- en una auténtica obsesión en nuestro mundo occidental. Dietas, productos adelgazantes... promesas de una vida supuestamente mejor. Como dice Josep Toro, a fuerza de ver modelos perfectos con una figura ideal y de escuchar mensajes sobre lo que es un cuerpo "nor- 
mal” estamos todos convenciéndonos de estar deformes, hipertróficos, gordos.

La delgadez normativa se configura como un valor supremo difícil de alcanzar para la mayoría de mortales. El canon estético imperante no es sólo una mera expresión cultural de la belleza propia de una época, sino que está peligrosamente asociado al éxito, al triunfo personal y social.

La anorexia y la bulimia son trastornos estrechamente vinculados a factores socioculturales, tal y como demuestran muchos estudios científicos. El hecho de que hasta bien entrado el siglo XIX no se conociesen desórdenes relacionados con el control de la alimentación tal y como los conocemos hoy para conseguir un determinado aspecto físico, es una buena prueba de ello. Los casos de ayuno voluntario anteriores al siglo XIX de los que se tiene constancia están ligados a motivos religiosos (de purificación). Curiosa paradoja. Cómo cambian los dioses por los cuáles merece la pena hacer sacrificios que, en muchos casos, llevan a la muerte. Además, los desórdenes alimenticios han penetrado en todas las edades, capas sociales y culturales. Hasta el punto de que sociedades en los que apenas se conocían estos trastornos empiezan a tener un número de casos que poco a poco se aproxima a los de Occidente.

La adolescencia es una etapa crítica, en el sentido de que es un momento clave para la (re)construcción y (re)definición de la propia identidad. En ese proceso, la imagen personal juega un papel trascendental. El desvelo por la belleza y la apariencia es importante en esta etapa, puesto que la preocupación por el cuerpo es una forma de afirmación personal y también un instrumento para aumentar la autoestima. Distintas investigaciones indican que un porcentaje altísimo de chicas adolescentes están descontentas con su cuerpo (también de mujeres adultas...). No es para menos. Los modelos de referencia - tan importantes para las y los adolescentes - suelen ser famosas extremadamente delgadas, algunas con medidas enfermizas. No hay tampoco muchos modelos corporales alternativos en los medios, figuras de éxito con distintas complexiones.

Los medios de comunicación son agentes muy importantes en la transmisión y potenciación de los mensajes sobre el anhelo de delgadez, un deseo presente de manera constante en los trastornos alimenticios. Los medios canalizan la presión social para estar delgado o delgada que, inequívocamente, es más fuerte sobre las mujeres que sobre los varones.

Por eso, nos parece imprescindible analizar los mensajes de los medios acerca de la belleza y el cuerpo desde una perspectiva de género. Debemos entender que, en lo que se refiere a nuestra apariencia y nuestro cuerpo, mujeres y hombres somos socializados de manera diferencial y asimétrica. Por esta razón hemos propuesto en estas páginas una reflexión crítica acerca de la experiencia corporal de las mujeres, de la renovada "mística de la feminidad", que 
las encierra en la cárcel de un cuerpo ideal

difícil de alcanzar.

\section{Referencias}

ARGENTE DEL CASTILLO, R. (1999). Anorexia y medios de comunicación. Revista de Estudios de Juventud, 47, 63-68.

CASTILlO PACHÓN, B. (2006). Sociedad de consumo y trastornos de la conducta alimentaria. Trastornos de la conducta alimentaria, 4, 321-335.

GRABE, S., WARD, L. M., Y HYDE, J. S. (2008). Role of the media in body image concerns among women: A meta-analysis of experimental and correlational studies. Psychological Bulletin, 134 (3), 460-476.

GUERRO-PRADO, D., y Barjau Romero, J. M. (2002). Television, printed mass media and their relationship with eating disorders. Medicina Clinica, 119 (17), 666-670.

GUERRO-PRADO, D., Barjau Romero, J. M., y Chinchilla Moreno, A. (2001). Epidemiología de los trastornos de la conducta alimentaria e influencia mediática: una revisión de la literatura. Actas Españolas de Psiquiatría, 29 (6), 403-410.

HUERTAS, A., Y FRANÇA, M. E. (2001). El espectador adolescente. Una aproximación a cómo contribuye la televisión en la construcción del yo. Zer, (11), 331-350.

IGARTUA, J. J., Y HUMANES, M. L. (2004). Teoría e investigación en Comunicación Social. Madrid: Síntesis.

KNAUSS, C., PAXTON, S. J., Y ALSAKER, F. D. (2007). Relationships amongst body dissatisfaction, internalisation of the media body ideal and perceived pressure from media in adolescent girls and boys. Body Image, 4 (4), 353-360.

KNAUSS, C., PAXTON, S. J., Y ALSAKER, F. D. (2008). Body dissatisfaction in adolescent boys and girls: Objectified body consciousness, internalization of the media body ideal and perceived pressure from media. Sex Roles, 59 (910), 633-643.
LÓPEZ FUENTETAJA, A. M., y Castro Masó, A. (2007). Adolescencia: Límites imprecisos. Madrid: Alianza.

MARTÍNEZ BENLLOCH, I., Y BONILLA CAMPOS, A. (2000). Sistema sexo/género, identidades y construcción de la subjetividad. Valencia: Universidad de Valencia.

PASTOR CARBALLO, R. (2004). Cuerpo y género: representación e imagen corporal. En E. Barberá Heredia y I. Martínez Benlloch (Eds.), Psicología y género (pp. 217-239). Madrid: Pearson Educación.

PLAZA, Juan. F. (2005). Modelos de varón y mujer en las revistas femeninas para adolescentes: la representación de los famosos. Madrid: Fundamentos.

PLAZA, Juan. F. (2007). El discurso del éxito en las revistas para las adolescentes. Revista de estudios de juventud, (78), 91-105.

THOMPSON, J. K., Y HEINBERG, L. J. (1999). The Media's Influence on Body Image Disturbance and Eating Disorders: We've Reviled Them, Now Can We Rehabilitate Them? Journal of Social Issues, 55 (2), 339-353.

TORO, J. (1996). El cuerpo como delito: anorexia, bulimia, cultura y sociedad. Barcelona: Ariel.

VENTURA, L. (2000). La tiranía de la belleza: las mujeres ante los modelos estéticos. Barcelona: Plaza Janés.

WOLF, N. (1991). El mito de la belleza. Barcelona: Emecé.

\section{Cita de este artículo}

PLAZA, J. F. (2010) Medios de comunicación, anorexia y bulimia. La difusión mediática del 'anhelo de delgadez': un análisis con perspectiva de género. Revista Icono14 [en línea] 1 de Octubre de 2010, Año 8, Vol. Especial. pp. 62-83. Recuperado (Fecha de acceso), de http://www.icono14.net 


\section{NOTAS}

${ }^{\mathrm{i}} \mathrm{Sin}$ duda, un libro de referencia sobre las relaciones entre anorexia, bulimia y factores socioculturales.

${ }^{\text {ii }}$ V'éase este tema desarrollado en Plaza (2005).

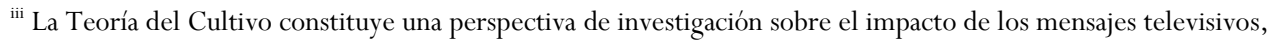
iniciada por George Gerbner y sus colaboradores a finales de la década de los sesenta. Aunque inicialmente se analizó el problema de la violencia, a medida que avanzaba se fueron incorporando otros tópicos como los estereotipos de género, raciales, sobre la ciencia y la salud, la política, etc. Mediante el Análisis del Cultivo se trata de determinar en qué medida la exposición a la televisión sirve de vehículo para el aprendizaje de nociones generales acerca de la realidad social. La Teoría del Cultivo se centra en determinar cuáles son las consecuencias sociales de los mensajes difundidos a través de la televisión. Se centra en investigar los efectos "no buscados" o "no intencionados" de la programación convencional de la televisión que está diseñada para "entretener" a la audiencia (como series y películas) (Igartua y Humanes, 2004). 